\title{
O ENSINO DE ARTE: DA CONTEXTUALIZAÇÃO HISTÓRICA ÀS ARTES PLÁSTICAS E HISTÓRIA DA ARTE NO CAP-UERJ
}

\author{
ARCURI, Christiane ${ }^{1}$
}

\section{RESUMO}

Neste artigo discorre-se, brevemente, sobre o histórico do ensino de Arte - desde às teorias expandidas nos Estados Unidos e na Europa até a sua difusão no Brasil. Arte como expressão e comunicação artísticas; como registro histórico-cultural; como aperfeiçoamento técnico-artístico; como um ofício de trabalho industrial até ao re-conhecimento de sua relevância nos ensinos escolar e acadêmico. Reporta-se a alguns aspectos relevantes na trajetória do ensino de Arte no CAp-UERJ, dos objetivos recorrentes à amplitude dos conteúdos ligados à cultura visual:da Arte educação à Educação Artística;das Artes Plásticas às Artes Visuais e História da Arte, na atualidade.

PalaVras-chave: Arte - Artes Visuais - Ensino.

\section{ABSTRACT}

This article discusses, briefly, about the Art of teaching history - from the theories expanded in the United States and Europe to its diffusion in Brazil. Art as expression and artistic communication; as historical and cultural record; as technical and artistic improvement; as an industrial working craft to the re-discovery of their relevance in school and academic teaching. It refers to some aspects relevant in the Art of teaching history in CAp-UERJ, the recurring goals to the breadth of content related to visual culture: Art education Arts Education; Plastic Arts to Visual Arts and Art History, nowadays.

KeYwORDS: Art - Visual Arts - Education.

\footnotetext{
${ }^{1}$ Professora Adjunta do Instituto de Aplicação Fernando Rodrigues da Silveira (CAp-UERJ). 


\section{INTRODUÇÃO}

Nesse artigo, discorremos sobre a trajetória histórico-pedagógica do ensinode Arte. Vemos como a Arte é desenvolvidaao longo dos tempos enquanto expressão e comunicação artísticas; como registro histórico-cultural; como aperfeiçoamento técnico-artístico; como um ofício de trabalho industrial até (finalmente) ao reconhecimentode sua relevância nos ensinos escolar e acadêmico.

Reportamo-nos à Arte quando expandida às escolas regulares - inicialmente como experimentação; em seguida, rumo à legalização e à obrigatoriedade nos ensinos formais; e mais adiante, nesse percurso, quanto às particularidadese especificidadesda Arte compreendida como Artes; Desenho Geométrico; Escolinha de Arte; Educação através da Arte; Arte educação; Educação Artística; Artes Plásticas; Artes Visuais e História da Arte.

Relacionar a história da evolução do ensino da Arte às especificidades da disciplina de Artes Plásticas e História da Arte no CAp-UERJfoi atribulado porque, no que concerne tanto aos registrosda história como aos documentos ínfimos e descontínuos do CAp,percebe-se que a importância dada à Arte não é mencionada de modo sucessivo e com a devida precisão que se pretende encontrar. Os comentários são intermitentes, além do que é notável que poucos autores se detiveramem ambas transcrições, o que acarretou numa repetição de informações resguardadas ao predomínio de poucos subsídios.

É relevante mencionar que a importância dada ao estudo da história do ensino de Arte se deve a amplitude no ensino de Arte no CAp-UERJ que, desde sempre,abrangeuas turmas regulares entre $01^{\circ}$ segmento do Ensino Fundamental e o $2^{\circ}$ ano do Ensino Médio. Com aulas semanais de cinquenta a cem minutos de acordo com a grade curricular correspondente ao ano de escolaridade -, a dis- ciplina teve como objetivo geral (dentre demais objetivos transcritos aqui) disseminar a cultura visual no decorrer da historiografia da arte ampliada na contemporaneidade.

\section{BREVE hISTÓRICO dO ENSINO DA ARTE - DAS TEORIAS EXPANDIDAS À SUA APLICABILIDADE NO BRASIL}

Com a chegada dos Jesuítas ao Brasil, no período colonial, a Arte foi enfatizada no ensino informal com o trabalho dos artesãos, dos índios, dos escravos e dos próprios Jesuítas. Os primeiros artistas, autodidatas,limitavam-se a copiar a Arte europeia.Da segunda metade do século XVI até o século XIX, a Arte na colônia erapraticada por negros ou mulatos e ensinada de pai para filho; ou de mestre para aprendiz.

Antonio de Araújo de Azevedo (1754-1817), o "Conde da Barca", considerado da elite intelectual, pretendeu montar uma Academia de Arte na colônia para atender a demanda da corte portuguesa recém chegada ao país, em 1808 . Chefiados pelo museólogo e crítico de Arte Joaquim Lebreton (1760-1819), a Missão Artística Francesa chegou ao Rio em 1816 e pareceu ser também um modo de institucionalização do ensino de Arte eque impôs a substituição do Barroco pelo Neoclássico.

A formação, de fato, da Academia Imperial de Belas Artes ocorreu em 1826 prevalecendo o método de ensino com traços da arte Neoclássica - que retomou os ideais greco-romanos e renascentistas , e tendo como fundamento principal o Desenho e a Escultura. Nessa época, a atividade artística não era incluída nas escolas públicas elementares e o ensino de Arte tornava-se uma exclusividade da Academia Imperial de Belas Artes.

Por volta do ano de 1855, Manuel José de Araújo Porto Alegre (1806-1879), 
pretendeu revigorar a educação elitista com modelos do Romantismo da então denominada Academia Imperial das BelasArtes. Através do contato com o povo pretendeu, com a sua reforma, conjugar no mesmo estabelecimento escolar duas classes de alunos - o artesão e o artista - a fim de que, ambas, frequentassem as mesmas disciplinas básicas. A formação do artista era alargada com outras disciplinas de caráter teórico, especializando-se o artífice nas aplicações do Desenho e na prática Mecânica.

Até 1870 pouco se contestouquanto à repetição dos modelos de ensino da Academia Imperial das Belas Artes - seguido pelas escolas secundárias particulares para meninos e meninas. A Arte reproduzia retratos de pessoas importantes, de santos, assim como a cópia de estampas, em geral europeias, que representavam paisagens muito diferentes ao meio ambiente tropical. Contrários ao uso da Arte na escola como adorno cultural, alguns liberais, principalmente na década de 1880, defenderam a ideia de que uma educação popular para o trabalho deviaser o principal objetivo da Arte na escola e iniciaram uma campanha para tornar o Desenho obrigatório no ensino primário e secundário. Deveu-se, portanto, aos liberais, o início do ensino do Desenho Industrial na escola - o que atualmenteaproxima-se do Design.

Na busca por um modelo que estabelecesse a união entre criação e técnica, ou seja, entre Arte e sua aplicabilidade à indústria, os intelectuais e políticos (especialmente os liberais) brasileiros se comprometeram com os modelos de Walter Smith para o ensino da Arte nos Estados Unidos. Difundidos por Rui Barbosa e pelo educador Abílio César Pereira Borges, que publicou o livro Geometria popular, uma espécie de sumário do Teacher's manual for free hand drawing, de Walter Smith (1873) que era adotado em escolas pelo menos até o ano de 1959. O objetivo do livro, explicitado por ele próprio, foi o de propagar o ensino do Desenho Geométrico de modo a educar a nação para o trabalho industrial. O estudo da Geometria ficou conhecido como "alfabeto do Desenho". O Desenho com modelos provenientes de ornamentos gregos; com elementos arquitetônicos inspirados no Barroco e no Neoclassicismo e, ainda, a análise de exemplos botânicos foram os mais aplicados.

$\mathrm{Na}$ escola tradicional valorizavamse, principalmente, as habilidades manuais, os "dons artísticos", os hábitos de organização e precisão, numa visão ao mesmo tempo utilitarista e imediatista da Arte. Os professores trabalhavam com exercícios e "modelos" convencionais selecionados por eles em manuais. O ensino de Arte voltado essencialmente para o domínio técnico, tinha a figura do professor como um "transmissor" aos alunos dos códigos, conceitos e categorias ligados a padrões estéticos resultantes na reprodução de modelos.

A Semana de Arte Moderna de 1922 foi o marco da introdução do Modernismo na Arte do Brasil não repercuti, de imediato, no ensino da Arte. O movimento de Arte educação surgiu com a influência de Dewey na Semana de Arte Moderna. Os princípios de Franz Cizek também contribuíram para a formação do movimento através de Anita Mafalti, que apoiada nas ideias "da livre-expressão" orientava as classes (informais) de Arte, em São Paulo. Assim como Mario de Andrade postulava, no curso de História da Arte na Biblioteca Municipal de São Paulo, que a Arte infantil como expressão espontânea devia ser estimulada.

Sob a influência da Escola Nova, por volta da década de 30 , surgiram no Brasil diversas obras que enfatizaram a educação sob aspectos psicológicos e sociológicos. As ideias de Dewey se propagaram no âmbito educacional brasileiro através de Anísio Teixeira.Essa pedagogia contrapunha-se à educação tradicional uma 
vez que os educadores que adotaramessa concepção acreditaram que as relações entre os indivíduos na sociedade podiam ser menos injustas se a educação escolar conseguisse adaptar os estudantes ao seu ambiente social. Para alcançar tais finalidades, propunha experiências cognitivas que deviam ocorrer de maneira progressiva, ativa, considerando os interesses individuais dos alunos.

A "educação através da Arte", expressão cunhada por Herbert Read, em 1943, se popularizou e, posteriormente, difundida comoArteeducação. Em 1954, Read fundou a International Society of Education Trought Art (INSEA) eestabeleceu que a Arte como base para a educação devia ter seus pressupostos na "educação estética". Autor da obra EducationThrought Art (1954), para ele, a finalidade da Arteeducação tinha como basea auto expressão - necessidade inata do indivíduo de comunicar-se com os demais por meio dos pensamentos; na observação, ou seja, através do registro(na memória) das impressões sensoriais paraclassificalascomo conhecimento conceitual do mundo; e, ainda, na apreciação - resposta dos indivíduos aos modos de expressão de outras pessoas e aos valores do mundo.

Por volta do ano de 1958, uma lei federal possibilitou e regulamentou a criação de classes experimentais. As experiências escolares surgidas nesta época visavam, sobretudo, investigar alternativas experimentando variáveis para os currículos e programas determinados como norma geral pelo Ministério de Educação. A presença da Arte nos currículos experimentais tornou-se uma demanda em profusão, quando destacavam-se os Colégios de Aplicação de várias universidades do Brasil.Entretanto, na prática, o ensino da Arte nas classes experimentais resultouna exploração de uma variedade de técnicas e de materiais de Pintura e de Desenho, respeitando as etapas de evolução gráfica das crianças - conformeas teorias difundidas de Viktor Lowenfeld e Herbert Read, assim como com o MEA Movimento de Escolinhas de Arte do Brasil -, criado em 1948 por Augusto Rodrigues, no Rio de Janeiro. A concepção desses autores deslocou o foco do ensino da Arte do produto para o processo; buscando justificar a importância da Arte na educação não pela Arte em si, mas na sua contribuição para a educação integral do ser humano.

As elaborações de Dewey (1958) acerca do conceito de Arte se inseriram no âmbito da Escola Progressiva dos Estados Unidos. A Escola Progressiva acompanhava os referenciais da Escola Nova europeia e propunhaa compreensão do saber constituído como"conhecimentos e vivências que se entrelaçavam de forma dinâmica, distante da previsibilidade das ideias anteriores"; alunos e professor detentores de experiências próprias, experiências essas aproveitadas no processo ensino aprendizagem. O professor possuía uma visão sintética dos conteúdos; os alunos uma visão sincrética - o que tornava a experiência, entre ambos, um ponto central na formação do conhecimento com uma aprendizagem essencialmente coletiva.

$\mathrm{Na}$ atualidade, as tendências da Arte educação, em um panorama nacional e internacional, podiam ser classificadas nos modelos do DBAE - Discipline Based Art Education. Originário nos Estados Unidos na década de 1960 e que tratava, de forma integrada, a produção, a crítica, a estética e a História da Arte, tendo como base dois enfoques pedagógicos: a Arte como expressão, com ênfase na livreexpressão, baseada em Lowenfeld e Read; e a Arte como comunicação, com ênfase na percepção e na linguagem, fundamentada em Arnheim, Feldman e Gombrich.

Entre 1960 e 1970, a tendência tecnicista se desenvolveu no Brasil no momento em que aeducação nacional era considerada insuficiente no preparo de profissionais para atender o mundo tecno- 
lógico em expansão. Inicialmente, essa tendência visava um acréscimo na eficiência da escola, objetivando a preparação de indivíduos mais competentes e produtivos conforme a solicitação do mercado de trabalho, a valorização do processo de industrialização e do desenvolvimento econômico. Coincidia com a implantação da disciplina de Educação Artística, a partir da publicação da Lei 5.692/71.

O ensino das Artes na educação básica, todavia, tornou-se obrigatório com a Lei no 5.692/71, que instituiu a disciplina Educação Artística nos currículos de $1^{\circ} \mathrm{e}$ 20 Graus (atualmente ensinos fundamental e médio). Tal obrigatoriedade ampliou a oferta de graduações (sobretudo as licenciaturas) com habilitações em Artes Plásticas, Artes Cênicas, Música e Desenho. Entretanto, essa mesma Lei também instituiu a polivalência do professor de Artes que deve ser um "generalista" e não um especialista em cada uma dessas linguagens artísticas.

Considerada como "atividade educativa", a Educação Artística não era reconhecida efetivamente enquanto uma disciplina. De todo modo, é relevante salientar que a introdução da Educação Artística no currículo escolar foi um avanço, principalmente se considerarmos que pouco a pouco o entendimento em relação à Arte na formação dos indivíduos eraampliada. No entanto, o resultado dessa proposição foi contraditório e paradoxal: muitos professores não estavam habilitados e, menos ainda, preparados para o domínio de várias linguagens que deveriam ser incluídas no conjunto do currículo escolar das "atividades" artísticas.

No entanto, apesar de instaurar a obrigatoriedade do ensino da arte na educação escolar, a Lei, ao designar os componentes do currículo, os classificava em duas modalidades: (1) Disciplinas - áreas do conhecimento com objetivos, conteúdos, metodologias e processo de avaliação específica; (2) e "Atividades"- desenvolvi- mento de práticas e de procedimentos. Isso posto, coube à Arte, inclusa no currículo escolar, desenvolver, apenas, os suposições de mera "atividade". Na prática, acreditava-se que ainda era a efetivação dorelutante tecnicismo pedagógico no ensino de Arte.

Eisner, em 1972, referiu-se a importância da interdisciplinaridade da Arteeducação para uma função educacional consistente. As abordagens essencialistas e contextualistas foram difundidas: a vertente contextualista considerava que o estudo da Arte, ao promover o desenvolvimento da percepção e da expressão, contribuindo para a construção da linguagem e da comunicação, do pensamento crítico e na aquisição de competências para a resolução de problemas. As metas e os conteúdos dos programas de Arte educação consideraram as características dos alunos e a comunidade como um todo social.

Os essencialistas, conceberam a Arte educação voltada para a natureza humana em geral. A importância está em si mesma, ou seja, sua importância se deve à relevância para os seres humanose não pelo fato de ser um instrumento para outros fins. Esta abordagem enfatizava a Arte comosendo o único caminho para integrar a experiência isolada com a experiência humana.

A partir de 1973 foram instituídos os cursos de licenciatura em Educação Artística com duração de dois anos (licenciatura curta) a fim da formação para estes professores "polivalentes". Após este curso, o professor mantinha seus estudos em direção à licenciatura plena, com habilitação específica em Artes Plásticas, Desenho, Artes Cênicas ou Música. Educação Artística é a nomenclatura que passou a designar o ensino polivalente nessas áreas. O Ministério de Educação organizou, em convênio com a Escolinha de Arte do Brasil, um curso para preparar os funcionários das Secretarias de Educação a fim de orientá-los para a implantação da nova 
disciplina. É neste curso que era um guia curricular de Educação Artística foi desenvolvido em cada estado brasileiro.

Em 1988, com a promulgação da Constituição, iniciaram-se as discussões sobre a nova Lei de Diretrizes e Bases da Educação Nacional, que foi sancionada em 20 de dezembro de 1996. Constatada a importância de acesso escolar dos alunos de ensino básico também à área de Arte, ocorreram manifestações e protestos de inúmeros educadores contrários a uma das versões da referida Lei, que retirou a obrigatoriedade da área.Com a Lei $n$. 9.394/96, revogaram-se as disposições anteriores e, a Arte, passou a ser considerada obrigatória na educação básica: "O ensino da arte constituirá componente curricular obrigatório, nos diversos níveis da educação básica, de forma a promover o desenvolvimento cultural dos alunos" (art. 26, § $2^{\circ}$ ).

Apesar da LDB de 96 reconhecer a Arte como uma área específica do conhecimento não existe à época, na formação de professores, o curso de Metodologia do Ensino de Arte e, como o MEC não possibilita por meio de concursos públicos para a rede de ensino a contratação de profissionais para atuarem nas escolas com as linguagens específicas, o profissional continua sendo polivalente.

Diante disso, a Federação de Arte educação do Brasil (FAEB), em 1996, exigiu através de uma carta de reivindicação enviada ao MEC e em diversos congressos, o estabelecimento de algumas diretrizes para delinear as linhas de conteúdos e métodos voltados para a formação artística e estética dos professores. A alegação foi a de que os mesmos necessitavam de outros conhecimentos em arte, para alargar tais noções e exercer a futura função de docente. Para a FAEB, o embasamento em Arte devia ser prático-teórico e experienciado durante toda graduação, com o predomínio da formação polivalente.
A integração da Arte no currículo escolar como uma área de conhecimento, sob a denominação de Ensino de Arte, foi oficializada na Resolução no 2, Câmara de Educação Básica (CEB) de 7 de abril de 1998, que institui as Diretrizes Curriculares Nacionais para o Ensino Fundamental, tendo em vista o disposto no Parecer CEB 4/9871 sobre a matéria. Essas Diretrizes conforme 0 art. $2^{\circ}$, são:

o conjunto de definições doutrinárias sobre princípios, fundamentos e procedimentos da educação básica [...] que orientarão as escolas brasileiras dos sistemas de ensino na organização, articulação, desenvolvimento e avaliação de suas propostas pedagógicas (BRASIL, 1998a).

A Resolução estabeleceu o currículo com uma base nacional comum e uma parte diversificada. O Ensino de Arte é uma das dez áreas de conhecimento que passaram a compor o currículo do Ensino Fundamental no Brasil.

O Parecer no 4/9872 e a Resolução no 2/98 da CEB estabeleceram sete diretrizes como referência para a organização do currículo escolar. Instituíram que as escolas deviam fundamentar suas ações pedagógicas em princípios éticos, políticos e estéticos. Estabeleceram como princípios complementares, a relação da autonomia, responsabilidade e solidariedade para a cidadania e a vida democrática. Também foram definidos como norteadores "os princípios da estética da sensibilidade, da criatividade e da diversidade de manifestações culturais e artísticas" (BRASIL, 1998a, p. 1).

"Arte-educação" e "Arte e ensino de Arte" estabeleceram a contiguidade entre Arte e educação nas escolas, nos espaços culturais, grupos e comunidades. Em 1998, os PCNs (Parâmetros Curriculares Nacionais) propõem categorias: Arte como expressão e comunicação; elemen- 
tos básicos formais; produtores de Arte; diversidade das formas de Arte e concepções estéticas da cultura regional; Arte na sociedade. Propondo os temas transversais, sendo um deles, a pluralidade cultural (visto como sinônimo de multiculturalidade). Os PCNs, nos impulsionam a "outras" buscas. A Proposta Triangular propôs uma relação tríade entre: ler obras de arte (crítica e estética), contextualizar as obras (relações entre Arte e outras áreas do conhecimento) e o fazer artístico (a prática plástica). Essa proposta foi fundamentada por Ana Mae Barbosa a partir de três abordagens epistemológicas: Escuelas ao Aire Libre, no México; Critical Studies, na Inglaterra (RodTaylor) e DBAE (Discipline Based Art Education), nos Estados Unidos (Elliot Eisner, Brent Wilson, Ralph Smith, Marjorie Wilson, entre outros). Desde então, um grande número de abordagens (com diferenças conceituais) ampliaram o enfoque entre o Olhar e a Leitura de imagens.

O que se pode perceber, até aqui, foi que a Arte/Educação tem se caracterizado como um campo amplo de conhecimento que durante a sua trajetória histórica e sócio epistemológica, vem agregando diferentes estudos - os quais são frutos de pesquisas científicas na área da Arte e seu ensino;em pesquisas artísticas e na produção de conhecimento/saberes; ou mesmo através da prática de ensino experimental de Arte, seja na educação escolar ou nãoescolar. Busca-se, por ora, compreender quais as tendências e concepções de ensino de Arte estão presentes na realidade educacional brasileira.

Diante as tendências vistas ao longo dos tempos, percebem-sediferentes concepções de ensino da Arte. Na tendência pré-modernista, desde a chegada dos Jesuítas, a concepção de ensino da Artecomo técnica; já na tendência modernista (por volta de 1900), a concepção de ensino daArte como expressão e também como atividade; e, posteriormente, na ten- dência pósmodernista (a partir dos anos 1970), a concepção de ensino da Arte como conhecimento.

Na contemporaneidade, a concepção de ensino de Arte como conhecimento vem sendo apontada pelos diferentes estudos. Oensino da Arte tem se desenvolvido de acordo com trêseixos norteadores: "fazer arte", ler imagens e contextualizálas no tempo-espaço. Estes (ainda) se referem à Proposta Triangular do ensino da arte sistematizada pela professora epesquisadora Ana Mae Barbosa no final dos anos de 1980: a construção doconhecimento no cruzamento entre experimentação, codificação e informação. No entanto, relacionar as tecnologias digitais - enquanto pesquisa, ferramenta e linguagem -, aos três eixos norteadores do processo ensino aprendizagem em Arte, pode ser um ponto de partida, acredita-se, consistente e didaticamente relevante para sua implementação nas propostas artísticoeducacionais da atualidade.

Reportamo-nos, contudo, a Hernandez (2000) que considerouo conhecimento artístico comoparte fundamental do conhecimento humano, visto as pesquisas sobre os processos de simbolização (GARDNER, 1994) e na relação com a Psicologia do desenvolvimento e o papel do conhecimento estético. Gardner indicou três aspectos que interatuam neste processo, na relação da arte ao desenvolvimento simbólico e expressivo: osistema de criação(enquanto ação)- do criador ou do intérprete; o sistema de percepção,quando as discriminações e distinções da esfera do crítico podem estabelecer relações; e o sistema de sensação,captados pelos órgãos do sentido. A interrelação entre esses sistemasé ampliada no processo deconstrução do conhecimento.Desse modo, espera-se que a construção do conhecimento em Arte seja contextual e interrelacional, quer dizer, através de relações significativas; da mesma forma, a interação e a apreensão da diversidade das manifesta- 
ções artísticas e tecnológicas da cultura visual também devem ser consideradas no âmbito do ensino em Artes Visuais e História da Arte.

\section{O ENSino de ARTE No CAP-UERJ: DA INSERÇÃO DA EDUCAÇÃO ARTÍSTICA ÀS ARTES VISUAIS E À HISTÓrIa dA ARTE NO INSTITUTO DE APLICAÇÃO}

A relevância desse levantamento histórico, que realizamos sobre o ensino de Arte ao longo dos tempos se deve à importância, que por ora se faz, de compilar os poucos registros até à atualidade a respeito da trajetória do ensino de Arte no CAp-UERJ.

O Colégio de Aplicação Fernando Rodrigues da Silveira da Universidade do Estado do Rio de Janeiro foi criado pelo Decreto Lei no 9053, de 12 de março de 1957. Como uma unidade vinculada ao Centro de Educação e Humanidades, a disciplina de Educação Artística (Artes Plásticas, Design e Fotografia) foiimplantada no Departamento de Educação Física e Artística.

Percebe-se uma história sobre o ensino de Arte no CAp-UERJ atrelada aos mais recorrentes pensamentos e tendências pedagógico-artísticos transcritos anteriormente nesse estudo.

Documentos que datam do ano de 1975,apontaram para um "Projeto de dinamização do ensino de Educação Artística do 20 grau" por um grupo de trabalho composto por Professores das áreas de Artes Plásticas, Música e Artes Cênicas.Como objetivos gerais da Educação Artística, os Professores definiram quatro objetivos "integradores": "compreender o mundo que o cerca"; "preservar o dado cultural"; "reagir criativamente a novos estímulos"; "integrar o conhecimento a formas de expressão".

No texto "Educação através da Arte" redigido pelo então Coordenador de
Arte Professor Luiz Antonio Ferreira, no ano de 1978, alguns conceitos básicos sobre Arte/Educação no CAp/UERJ nortearam

o trabalho de educação artística com base na expressão e apreciação; experiência e observação. Expressão aqui compreendida como processo de desenvolvimento individual e pessoal organizando sentimentos e ideias e apreciação, observação do produto de atividades artísticas que conduzem ao entendimento da Arte como fenômeno humano, artístico e cultural. Dessa maneira, exploramos Educação através da Arte em dois enfoques principais - como processo, ligada a objetivos da psicologia do indivíduo e da educação, enfatizados na prática da Arte: executar e produzir trabalhos de Arte, ver e sentir as relações da matéria artística, apreciando-as criticamente; como produto, ligada especificamente às disciplinas de Arte, realçadas na observação e compreensão da produção artística (o que acontece principalmente no $2^{\circ}$ grau, em Apreciação, Estética ou Arte e História do Homem).

(...) A Educação através da Arte, assim como tudo o mais, se encontra em período transitório, de redefinições. Não podemos contentar-nos em olhar para trás com nostalgia, nem aceitarmos indiscriminadamente tudo que é novo e diferente. Assim como os artistas contemporâneos devem entrosar-se com o seu ambiente, o trabalho de Arte/Educação precisa confrontar, avaliar e agir com base na experiência atual.

Esses conceitos permanecem até hoje na disciplina de Arte Visuais no CAp: a fuga aos chamados trabalhos de Arte que não supõem criação, autonomia, iniciativa e individualidade. 
No ano de 1980, o Professor Welitom Vieira Santos, então Vice-Diretor e Coordenador do Serviço de Orientação Pedagógica,redigiu um texto a partir das reflexões de professores e pais de alunos, como mencionou. Alguns "objetivos"do Colégio de Aplicação foram enumerados. Apesar de não serem relacionadas diretamente à Educação Artística percebe-se que,em alguns abaixo em destaque, eram relevantes para a área:

(3) Desenvolver o espírito crítico, fazendo o aluno analisar as informações, os dados que the são trazidos, desestimulando a crença pura e simples nos conteúdos que vêm nos livros ou que são transmitidos pelo professor; (4) Discuti-los, levar o aluno a uma reflexão permanentemente frente à superficialidade e autenticidade das informações e mensagens dos meios de comunicação de massa; (5) Estimular a resposta original, a busca de soluções menos comuns, a procura de alternativas para uma mesma situação, a prontidão para resolver problemas e situações novas; (6) Fazer o aluno desenvolver uma expressão correta e original quanto possível. Convencê-lo de que, à medida que enriquece sua linguagem ele enriquece o mundo e seu mundo. Suas percepções se tornarão mais amplas, possibilitando múltiplas leituras do universo.

Entendemos que "desenvolver o espírito crítico" é ampliar para o aluno, nas aulas de arte, os parâmetros que o norteiem a perceber que a apreciação e a avaliação das informações e mensagens dos meios de comunicação de massa cotidianas são fundamentais para sentir-se inserido e predisposto culturalmente. Pensando assim, "estimular a resposta original" é dar subterfúgios estéticos e artísticos para o aluno conquiste uma abordagem mais dinâmica e criativa para os estímulos visuais da contemporaneidade.
Na reunião do Conselho Pedagógico realizado em 19850 Professor, o então Diretor João Álvaro Ferreira destacouna alínea f: "No espírito crítico indispensável às responsabilidades da aprendizagem integral que, no entanto, não deve sobrepor-se à fertilidade da auto crítica, no diálogo educativo" como um dos aspectos a serem considerados quanto à filosofia educacional do CAp.

Por ocasião do aniversário dos 40 do Colégio de Aplicação, no Boletim Informativo de 1997, a então Diretora Professora Maria Lúcia Weiss, escreveu:

Não se falava em Festa do Folclore sem colaboração da Educação Artística, não existia o Teatro sem Comunicação e Expressão, sem Artes Plásticas. (...) Exposições permanentes de Artes Plásticas, (....) no ano de 1976 (...) os prédios da rua Haddock Lobo 269 (...) instalamosum Clube de cinema (...), e também um laboratório de fotografia, sala de artes industriais (...). O primeiro segmento foi planejado com um curso modelo, além das professoras regentes de cada turma, contratamos professores especializados em Música, Artes Plásticas (...).

Ao ingressar na equipe de Educação Artística(Artes Plásticas), no ano de 1997, pude perceber de perto que essas eram práticas comuns no CAp. As muitas linguagens artísticas destacavam-se ao desenvolverem os muitos projetos na escola e as parcerias com demais áreas do conhecimento eram favoráveis. O apreço dos demais professores e funcionários eram respaldados pela direção.

Ainda nesse mesmo ano de 1997, as ementas da disciplina de Artes Plásticas referentes da $5^{a}$ à $7^{a}$ séries do $1^{0} \mathrm{grau}-$ o que correspondem atualmente ao $2^{\circ}$ segmento do ensino fundamental - apresentaram como os objetivos gerais: "fazer e criar formas entendendo melhor as ma- 
nifestações artísticas visuais"; "conhecer, analisar e comparar obras de artistas contemporâneos e do passado e compreendêlas nas suas inserções culturais". O conteúdo programático tinha por base a Metodologia Triangular de Ana Mae Barbosa (1991): o fazer artístico, a apreciação e contextualização da cultura artística - além da arte entendida através da sua funcionalidade enquanto expressão, trabalho e comunicação.

No texto "Orientação teórica para desenvolvimento de uma prática pedagógica em Arte no CAp UERJ", elaborado pela Professora de Música Ilana Linhales Rangel a partir de depoimentos dos Professores da equipe de Arte, no ano 2001, lemos:

O trabalho com Arte pretende que os sujeitos desenvolvam sua autonomia possibilitando a dúvida e o erro e encarando-os como possíveis descobertas para novos caminhos e, por fim, reconhecendo-os e expressando-se nele de forma comprometida através de ações e opções conscientes.

O trabalho com Arte no CAp UERJ então, se destina a orientar os sujeitos no sentido de deixar aflorar neles as suas próprias maneiras de ver, de ouvir e de sentir o mundo e de traduzi-lo a partir da linguagem artística apreendida através de uma prática pedagógica (...).

É na prática pedagógica que estão as buscas de respostas para seus próprios questionamentos e precisamos entendê-la como um ponto de partida e um espaço de teoria em movimento permanente de construção, desconstrução e reconstrução.

Percebe-se que os fundamentos da Arte institucionalizados até então no CApsão retomados. No que concerne ao estímulo de alunos mais participativos, criativos e críticos acerca das demandas imagéticas cotidianas. Estimula-se a subjetivida- de e a argumentação estético-visual. O espaço das aulas de artes tornam-se propícias para que o aluno perceba novas maneiras de ver o cotidiano que o cerca.

No ano de 2003, a equipe de Artes reescreveu o texto anterior e intitulouo novo texto como "Sobre o ensino de Arte":

A Arte apresenta-se para os sujeitos colaborando para o conhecimento socialmente construído; possibilita a ampliação de suas capacidades de (re) conhecimento quando atuante continuamente sobre os diferentes objetos de conhecimento; relaciona dados, fatos e conceitos das diversas ciências, utilizando os conhecimentos adquiridos como instrumento de reflexão crítica, de modo criativo, a estereótipos e padrões rígidos no que diz respeito à estética cultural.

Entende-se aqui o pensamento como capacidade de conhecer e de estabelecer relações. Intuição, como radar do mundo interno apontando o que, por nós, precisa ser sentido. Imaginação, como flexibilidade de composições e investigação de possibilidades. $E$, sensibilidade, como canal aberto de captações do mundo externo para o interno, algo que, como disse Sócrates, um dia acerca de tal virtude, não pode ser ensinada, mas aprendida.

(...) É preciso ressaltar que o ensino de Arte vem colaborar para o desenvolvimento de sujeitos (...) capazes (...) de entender e dinamizar criticamente o mundo em que vivem.

Pode-se dizer que, até o presente momento, esse foi o último texto pensado coletivamente e registrado pela equipe de Artes. Acredita-se, portanto, que sua ideia central sobre os fundamentos e as caracterizações do ensino estejam sendo permanentemente difundidos por sua atuante equipe. 
No entanto, é importante reportarmo-nos, ainda, ao ano de 2004, quando a revisão e atualização das ementas - até então vigorantes - apontaram para objetivos que restringem o ensino de Artes Plásticas de $1^{a}$ a $7^{a}$ séries do $1^{\circ}$ grau (hoje $1^{\circ}$ e $2^{\circ}$ segmentos do Ensino Fundamental) à vivência plástico-visual dos elementos da forma perceptiva ainda atrelados à citada Metodologia Triangular. No Ensino Médio, os objetivos do $1^{\circ}$ ano destacam:

Proporcionar o conhecimento visual de fatos históricos e movimentos artísticos relevantes na História da Arte no Brasil; Estimular uma visão crítica dos acontecimentos histórico-artísticos desde o descobrimento até à contemporaneidade; Possibilitar que os alunos criem suas próprias reflexões plásticas.

No 20 ano do Ensino Médio, na disciplina de História da Arte, os objetivos gerais apontavam:

Compreender, analisar e discernir a produção visual em seu contexto histórico; Relacionar a representação visual na periodicidade histórica e cultural com a contemporaneidade; Reconhecer o valor histórico-social-estético-artístico em todas as fases da produção da História da Arte; Analisar todas as formas de linguagem que vêm anteriormente aos períodos estudados.

Com a amplitude da equipe, no ano de 2012, outra (nova) proposta curricular foi articulada. Os objetivos da disciplina não eram diferentes dos até então vigentes, mas o programa em si, no que concerne aos assuntos teórico-práticos a serem desenvolvidos, foramre-pensados de modo que a cultura visual à época do Modernismo do Brasil merecesse maior destaque, incluindo-se suas possíveis articulações estéticas com a contemporaneidade.
A análise da percepção da forma e o desenvolvimento plástico dos elementos da linguagem visual também continuaram a ser de extrema relevância, principalmente nas aulas do primeiro segmento do Ensino Fundamental.

O que pareceu-nos de extrema importância, até então,foi a oportunidade desse registro sobre o ensino de Artes Visuais e História da Arte no CAp-UERJ a partir do breve panorama dodesenvolvimento do ensino de Arte.No decorrer do levantamento que realizamos, destacaramsecomo fundamentos epistemológicos da disciplina a prática dapercepção visual, a reflexão plástica e a imaginação crítica referentes à cultura visual das civilizações.

Buscou-se, através do ensino de Artes, contribuir para a construção de uma comunidade escolar em que a dimensão ética e estética estivessemvalorizadas e que a expressividade do aluno fosse condizente com os seus anseios mais subjetivos, respeitando a coletividade.

Sendo assim, alguns objetivos tornaram-se fundamentais nas ementas de Artes Visuais e História da Arte em vigor na atualidade, tais como: conhecer as dimensões culturais das regiões brasileiras para o reconhecimento da importância da formação da cidadania e da identidade nacionais; valorizar e respeitar a pluralidade do patrimônio histórico e cultural no Brasil e no mundo; excluir os padrões estereotipados e os modelos préestabelecidos em favor de uma poética visual singular; compreender a Cultura Visual para possíveis relações, proposiçõese questionamentos; distinguir a importância da diversidade estética das expressões artísticas nos campos do desenho, da pintura, colagem, escultura, gravura, design, cinema e vídeo, fotografia, histórias em quadrinhos e charges, grafite, instalações, performances, dentre outras; perceber-se como agente crítico e transformador do cotidiano; experimentar as diferentes linguagens artísticas como meio de 
percepção, reflexão e expressãocomunicação de ideias subjetivas; considerar as propriedades expressivas e construtivas dos materiais, suportes, instrumentos, procedimentos e técnicas na produção de formas visuais em sala de aula e em museus, mostras de arte, exposições, galerias, ateliês, oficinas, etc.; experimentar, utilizar e pesquisar materiais e técnicas artísticas tais como pincéis, lápis, giz de cera, papéis, tintas, argila, goivas assim como máquinas fotográficas, vídeos e informática...

A educação em Artes Visuais e História da Arte no CAp-UERJ, todavia, pretende propiciar aos alunos o entendimento valorativo da história das civilizações através do conhecimento dos seus movimentos artísticos e estilos estéticos desenvolvidos ao longo dos tempos. Ampliando o estudo sobre a diversidade artística, espera-se que os alunos compreendam a manifestação e real necessidade de cada cultura ao revelarem-se por meio de seus valores e dos seus significados. Através da matéria curricular de Artes Visuais e História da Arte nessa instituição de ensino, percebe-se que os alunos podem ser levados ao autoconhecimento a fim de que ajam criticamente nas intervenções e nas ingerências artístico-culturais da sociedade em que vivem.

\section{AGRADECIMENTOS}

Em tempo, um especial agradecimento a Profa. Lula Rufino, de Design Gráfico, por ter disponibilizado alguns dos (poucos e raros) documentos que registram essa trajetória do ensino de Arte no CAp-UERJ.

\section{REFERÊNCIAS BIBLIOGRÁFICAS}

BARBOSA, Ana Mae. A Arte-Educação no Brasil: das origens ao Modernismo. São
Paulo: Perspectiva, 1994.

- Arte-Educação: conflitos/acertos.

São Paulo: Max Limonad, 1984.

Arte-Educação no Brasil: das

origens ao modernismo. São Paulo: Perspectiva, 1986.

. Ensino da Arte: memória e história.

São Paulo: Perspectiva, 2008.

. John Dewey e o ensino da Arte no

Brasil. São Paulo: Cortez, 2001.

; SALES, H. M. (Org.). O ensino da Arte e sua história. São Paulo: MAC-USP, 1990.

BRASIL. Lei n. 0 5.692/71. Estabelece as Diretrizes e Bases da Educação Nacional Brasília, 1971.

BRASIL. Lei no 9.394/96. Estabelece as Diretrizes e Bases da Educação Nacional. Brasília, 1996.

BRASIL. MEC. Parâmetros Curriculares Nacionais. Documento Introdutório. Brasília: MEC/SEF, 1998c.

. Parâmetros Curriculares Nacionais: Arte. Brasília: MEC/SEF, 1998d.

COUTINHO, R. Qual o lugar da arte na educação? In CHRISTOV, L.H.S. e MATTOS, S. R. Arte-Educação: experiências, questões e possibilidades. São Paulo: Expressão e Arte Editora, 2006.

DONDIS, D. A. Sintaxe da linguagem visual. São Paulo: Martins Fontes, 2000.

DUARTE JR, J. F. Por que Arte-Educação? Campinas: Papirus, 1983.

FERRAZ, M. H.; FUSARI, M. F. Metodologia do ensino da Arte. São Paulo: Cortez, 1993. 
FISCHER, E. $A$ necessidade da Arte. Rio de Janeiro: Guanabara, 1987.

FUSARI, M. F.; FERRAZ, M. H. A Arte na educação escolar. São Paulo: Cortez, 1992.

GARDNER, H. Inteligências múltiplas: a teoria e a prática. Porto Alegre: Artes Médicas, 1994.

HERNÁNDEZ, F. Catadores da cultura visual: proposta para uma nova narrativa educacional. Porto Alegre: Mediação, 2007.

- Cultura visual, mudança educativa e projeto de trabalho. Porto Alegre: Artmed, 2000.

LÉVY, P. As tecnologias da inteligência: o futuro do pensamento na era da informática. São Paulo: Editora 34, 2002. MARTINS, M.C. et al. Didática do ensino de Arte: a língua do mundo, poetizar, fruir e compreender arte. São Paulo: FTD, 1998.

ZANINI, W. História Geral da Arte no Brasil. São Paulo: Instituto Walter Moreira Salles, 1983. 2 v. 